\title{
LA NOCIÓN DE LIBERTAD DE CÁTEDRA EN LA C. A. EX CORDE ECCLESIAE Y SU VIGENCIA CONTEMPORÁNEA
}

\author{
THE CONCEPT OF ACADEMIC FREEDOM IN A. C. EX CORDE \\ ECCLESIAE AND ITS CONTEMPORANEOUS VALIDITY
}

\author{
RAÚl MADRID RAMÍREZ
}

\begin{abstract}
RESUMEN: El objeto de este trabajo es exponer el concepto, contenido y límites de la noción de libertad de cátedra en la Constitución Apostólica Ex Corde Ecclesiae, y de qué manera, al estar asociada a la verdad en sentido metafísico y teológico, puede ser un horizonte hermenéutico adecuado para enfrentar los problemas de la universidad contemporánea; con su complejidad estructural, la necesaria convivencia con el pluralismo ideológico y la multiculturalidad. El artículo hace especial hincapié en la consideración epocal, y en la dialéctica que se establece entre fe, razón y verdad; consideradas no solo en su dimensión abstracta, sino en la perspectiva práctica de los conflictos que se pueden producir al interior de la academia confesional. Destaca entre las conclusiones que la Iglesia, al aceptar la legítima autonomía de la cultura humana y especialmente de las ciencias, reconoce también la libertad de cada estudioso en la disciplina de su competencia, de acuerdo con los principios y métodos de la ciencia a la que ella se refiere, pero inscritas en el paradigma hermenéutico de las exigencias de la verdad y del bien común
\end{abstract}

Palabras clave: Libertad de cátedra, Universidad Católica, Identidad Católica.

ABSTRACT: The object of this paper is to elucidate the concept, content and limits of academic freedom in Ex Corde Ecclesiae, and to analyze in which sense it could become an hermeneutic horizon to challenge contemporary issues of postmodern universities, such as structural complexity, the inevitable pluralism of ideologies and multiculturality. The work specially stresses the "epochal" perspective, and the dialectical relation between faith, reason and truth considered both in abstract and practical scope inside the catholic academy. The conclusions intend to show that the Church, by accepting the rightful autonomy of human culture, and specially that of science, acknowledges the freedom of every academician in his own field of inquiry as well, according to the principles and methods of his discipline, under the hermeneutic pattern of the exigences of truth and common good.

Key words: Academic Freedom, Catholic University, Catholic identity.

Doctor en Derecho y Magíster en Filosofía por la Universidad de Navarra. Profesor Titular Ordinario de la Pontificia Universidad Católica de Chile. Dirección postal: Av. Libertador Bernardo O’Higgins 340, Facultad de Derecho, Santiago de Chile. Dirección electrónica: rmadrid@uc.cl

Este trabajo forma parte del Proyecto FONDECYT No 1141143, titulado "El derecho a la libertad de cátedra y la evolucion del concepto de universidad. tres modelos para una misma garantía”, del cual el autor es investigador principal. 


\section{INTRODUCCIÓN}

Cumplido el vigésimo quinto aniversario de la Constitución Apostólica Ex Corde Ecclesiae (en adelante, ECE), parece conveniente relexionar sobre los aspectos más significativos de su contenido, a la luz de los acontecimientos y los modelos de pensamiento en el debate público de las libertades de nuestro tiempo. Hoy los centros universitarios enfrentan desafíos nuevos sobre problemas antiguos - merced a la radical perspectiva que supone asumir los postulados del postestructuralismo-, entre los cuales destaca de manera significativa la garantía de libertad de cátedra, cuya interpretación contemporánea hace prácticamente imposible su adecuación al diálogo entre ciencia y fe $\mathrm{f}^{1}$. Las unversidades, para ser reconocidas como tales, tendrían la obligación de huir de los "autoritarismos dogmáticos", y comprometerse necesariamente con la "libertad intelectual" y el escepticismo metodológico 2 .

La normalización de estas conclusiones dentro de los estándares de corrección política que operan en la esfera pública del mundo occidental, hace indispensable, en nuestra opinión, una reconfiguración del concepto de libertad de cátedra, que permita el replanteamiento de esta en el horizonte de significado que proviene de la Revelación, y que se abre al mundo postmoderno con la misma vocación con que lo hizo a los anteriores paradigmas histórico-culturales, es decir, desde los principios.

La libertad de cátedra es una noción doctrinalmente compleja, que ha sufrido sucesivas modificaciones en la determinación de su contenido a lo largo de la historia; asociadas a los distintos modelos hermenéuticos en la comprensión de la universidad, que determinan de un modo relevante su naturaleza, contenido y límites ${ }^{3}$. Es por esto que la explicitación de tales características en las universidades católicas, por causa del devenir histórico-cultural del mundo occidental, requiere de una especial mirada a su misión y objetivos institucionales.

La universidad medieval, que es la universidad católica misma, por cuanto se remonta al propio origen de la universidad como institución, tenía por objeto o fin institucional el gaudium de veritate agustiniano; es decir, "el gozo de buscar la verdad, de descubrirla y de comunicarla en todos los campos del conocimiento" 4 . La idea de la verdad que representa el horizonte de significado de la universidad católica, y que, consecuentemente, determinará también su noción de libertad de cátedra, consiste no solo en la verdad que se puede alcanzar por el simple uso de la inteligencia natural, sino también aquella que es entregada

\footnotetext{
Cf. por ejemplo la idea de que la posibilidad de establecer un límite a la libertad académica se encuentra sometida a la lógica del suplemento, y por lo tanto puede ser deconstruida porque resulta indecidible. DERRIDA (1985) pp. 89 y ss.

2 O'Brien (2002) p. 1.

3 MADrid (2013) p. 355.

4 ECE, n. 1. Como sostiene Ruegg, "la función práctica postula la importancia fundamental del amor sciendi. Si no fuera así, la universidad, entendida como una corporación que sirve solo intereses y libertades materiales, habría compartido el destino de otras instituciones medievales, y habría desaparecido hace mucho tiempo. Fue la responsabilidad colectiva para la organización y disciplina de la búsqueda del conocimiento, del studium, lo que otorgó significado a las libertades y privilegios de los académicos y maestros, trascendiendo sus intereses materiales inmediatos, y asegurando la persistencia de la autonomía de la universidad en su actividad más propia, que es la investigación y la docencia académica”. RuegG (1992) p. 23.
} 
al hombre por la fe. Como recuerda Pedro Morandé, San Agustín pensaba que el gozo de la verdad era el gozo de Dios mismo5. Por eso, uno de los elementos necesarios que esta debe poseer es "una reflexión continua, a la luz de la fe católica, sobre el creciente tesoro del saber humano, al que trata de ofrecer una contribución con las propias investigaciones". Ello se traduce en la exigencia de garantizar institucionalmente la presencia cristiana en el mundo universitario, en especial, frente a los grandes problemas que afectan a la sociedad y a la cultura ${ }^{6}$, y también al diálogo del Evangelio con las diferentes culturas ${ }^{7}$. Así pues, se dice que la misión fundamental de la universidad es la constante búsqueda de la verdad mediante la investigación, la conservación y la comunicación del saber para el bien de la sociedad $^{8}$. La universidad católica tiene, a través de ello, la obligación de intentar ofrecer una respuesta a los problemas de su horizonte epocal. Esto supone tanto la exigencia de una cabal comprensión de ellos, como la capacidad de descifrarlos a la luz de los grandes principios que la sustentan, generando para tal objetivo las propuestas metodológicas que sean necesarias. Es en este horizonte de significado que debe entenderse la noción de libertad de cátedra que propone la Constitución Apostólica: como un criterio de acción que ofrezca respuestas coherentes con el Magisterio a las aporías presentadas por la encrucijada histórico-cultural sobre las libertades y límites de los académicos. En este sentido, se trata de una noción dinámica, no estática, en que se resalta su dimensión de razón práctica.

Este objetivo específico y propio de la universidad se une a la misión general de contribuir "de un modo riguroso y crítico a la tutela y desarrollo de la dignidad humana y de la herencia cultural mediante la investigación, la enseñanza y los diversos servicios ofrecidos a las comunidades locales, nacionales e internacionales" ${ }^{\prime}$. En este párrafo se encuentran contenidas las funciones clásicas asignadas a los centros universitarios: la producción de conocimiento; la comunicación del conocimiento y la difusión de los saberes para provecho de la sociedad civil. Estas actividades propias de la universidad deben contribuir a la tutela y desarrollo de la dignidad humana y de la herencia cultural. La redacción sugiere que la herencia cultural que desarrolla la universidad debe ser coherente con el contenido de la dignidad humana; esta actuaría como límite de dicha herencia, que debe ser transmitida y desarrollada por las universidades. Por lo tanto, no es erróneo afirmar que la dignidad de todos los seres humanos es un horizonte de significado, un criterio hermenéutico de las actividades de la universidad; se halla en el corazón mismo de esta. Tal conclusión entronca con Gaudium et Spes, donde se afirma la singular dignidad de la persona humana, la cual es la única criatura en la tierra "a la que Dios ha amado por sí misma" ${ }^{\text {. }}$

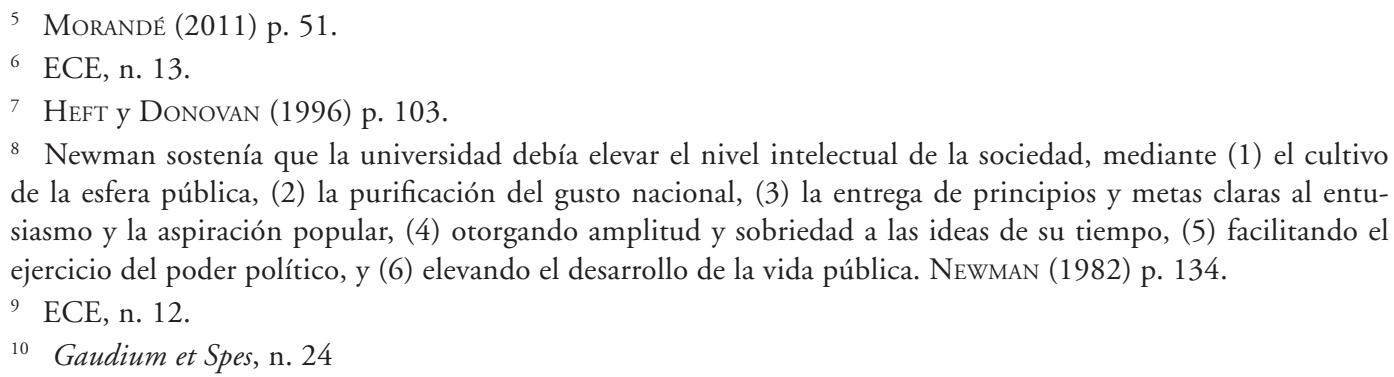
de la esfera pública, (2) la purificación del gusto nacional, (3) la entrega de principios y metas claras al entusiasmo y la aspiración popular, (4) otorgando amplitud y sobriedad a las ideas de su tiempo, (5) facilitando el ejercicio del poder político, y (6) elevando el desarrollo de la vida pública. NEWMAN (1982) p. 134. 
Ahora bien, como lo anterior se predica de la universidad católica en cuanto universidad, cabe entender la idea de dignidad humana en cuanto procedente también de una conclusión de razón natural, por cuanto el hombre ha recibido en su naturaleza el gran regalo de su inteligencia y libertad ${ }^{11}$; sin perjuicio de que, en el caso específico de las universidades católicas, se vea completada con la dimensión trascendente de esa dignidad que radica en la naturaleza, la cual adquiere su pleno sentido en la noción de "persona".

\section{LA LIBERTAD DE CÁTEDRA}

Para cumplir su tarea, la universidad requiere de autonomía institucional; esta es condición para que se produzcan dos resultados: (a) que la universidad pueda desempeñar sus funciones de manera eficaz, y (b) que pueda garantizar a sus miembros la libertad académica. Esto último tiene como límite -sostiene la Constitución Apostólica- los derechos de la persona y de la comunidad, dentro de las exigencias de la verdad y del bien común ${ }^{12}$.

La autonomía institucional de la universidad consiste en la potestad de proveer los intereses propios, y de disponer de los medios necesarios para satisfacerlos. Se trata de una cierta libertad de autodisposición sobre los asuntos o materias que afectan dichos intereses específicos; consiste en una relativa independencia normativa y política ${ }^{13}$. Su carácter limi-

11 Veritatis Splendor, n. 38: "citando las palabras del Eclesiástico, el concilio Vaticano II explica así la "verdadera libertad» que en el hombre es «signo eminente de la imagen divina»: "Quiso Dios "dejar al hombre en manos de su propio albedrío", de modo que busque sin coacciones a su Creador y, adhiriéndose a él, llegue libremente a la plena y feliz perfección» 64. Estas palabras indican la maravillosa profundidad de la participación en la soberanía divina, a la que el hombre ha sido llamado; indican que la soberanía del hombre se extiende, en cierto modo, sobre el hombre mismo. Este es un aspecto puesto de relieve constantemente en la reflexión teológica sobre la libertad humana, interpretada en los términos de una forma de realeza. Dice, por ejemplo, san Gregorio Niseno: «El ánimo manifiesta su realeza y excelencia... en su estar sin dueño y libre, gobernándose autocráticamente con su voluntad. ¿De quién más es propio esto sino del rey?... Así la naturaleza humana, creada para ser dueña de las demás criaturas, por la semejanza con el soberano del universo fue constituida como una viva imagen, partícipe de la dignidad y del nombre del Arquetipo".

12 ECE, n. 12.

13 La autonomía universitaria es la dimensión institucional de la libertad de cátedra. La noción de autonomía tiene un carácter polisémico, pero cuando se usa respecto de la universidad quiere decir fundamentalmente autonomía política y administrativa, lo que supone el reconocimiento de un núcleo de intereses propios -esencialmente indisponibles-. Esta autonomía es singular, de cada universidad, y no se predica de la institución universitaria, entendida como idea abstracta o conjunto de universidades. ¿En qué consiste la autonomía política? En la capacidad de tomar decisiones generales que afecten a toda la universidad. Es una potestad de plena decisión, dentro del marco constitucional. Es decir, consiste en la potestad legislativa interna. La autonomía administrativa, por su parte, consiste en una consideración igualmente normativa, pero de carácter menos general: la potestad de autodeterminarse relativamente, concedida por quien tiene a su cargo la autodeterminación soberana, y en base a la libertad esencial y natural de todos los seres humanos. Esta "potestad legislativa" de los entes autónomos dentro del Estado -como dicen Leguina y Ortega-, no alcanza realmente nunca, por definición, el rango legislativo, sino que se sitúan en un plano simplemente reglamentario, subordinado a las leyes. Cf. Leguina y Ortega (1982) p. 550. La autonomía se debe entender, pues, en dos dimensiones: ad intra, es decir, todo lo relativo al gobierno de la institución, y ad extra, respecto de la autoridad de que esta depende. En la universidad católica el límite respecto de la Iglesia es el Magisterio, que supone la libertad de investigación y de enseñanza, respetando los Estatutos de la respectiva universidad. Asimismo el respeto y equilibrio que debe existir respecto de la ley civil en todo lo que se refiere a los planes de estudio y grados que se otorgan. SiLva (2009) p. 271. 
tado o relativo indica su sujeción al poder político, y al Derecho Público ${ }^{14}$. Esta cuestión, de naturaleza jurídica, tuvo gran relevancia a propósito de la universidad moderna, cuya relación con los gobernantes civiles, o los propietarios de ella, no siempre fue pacífica ${ }^{15}$. En la época contemporánea, la presión por la autonomía de las universidades católicas se intensifica, principalmente en Estados Unidos, con el despido que realiza la Saint John's University (Nueva York) de dos docenas de profesores disidentes en la Facultad de Teología, en 1965 , lo que produjo un enorme revuelo y reinstaló el tema en el debate público ${ }^{16}$.

La mencionada autonomía institucional adquiere hoy en día dimensiones más complejas; por cuanto los modos en que terceros pueden interferir en la administración y conducción de la universidad en el tiempo presente van más allá de la independencia formalmente establecida, en categoría de exigencia jurídica. Debido a la fragmentación del ámbito público, y la proliferación de operadores en el escenario nacional e internacional, la autonomía universitaria del siglo XXI debe enfrentar obstáculos de una densidad superior a la de tiempos pasados. Esta autonomía es todavía más frágil en el caso de las universidades católicas, por cuanto la mayoría de estos operadores (ONGs, lobbies, transnacionales, criterios de corrección política, etc.) encarnan pensamientos, doctrinas y partisanismos de signo opuesto los valores cristianos ${ }^{17}$; a veces con abrumador dominio de los medios de comunicación. La independencia a que se refiere la Ex Corde Ecclesiae requiere, en este sentido, de una incardinación hermenéutica de los principios que la sostienen, para formalizarse de un modo realmente operativo respecto de estas amenazas, que no por ser más sutiles aparecen como menos contundentes. Dicho de un modo más claro, es necesario proceder a analizar las diversas limitaciones contemporáneas que se quieren imponer a las universidades católicas, dentro de las cuales la más importante es, sin duda, su sometimiento a los criterios de corrección política ${ }^{18}$.

La autonomía institucional de la universidad, afirma ECE, garantiza la libertad académica ${ }^{19}$. Para efectos de la Constitución Apostólica, las nociones de "libertad académica" y "libertad de cátedra" se presentan como sinónimos; aunque en sentido técnico sean diferentes, pues la autonomía es la dimensión institucional de la libertad académica,

14 López-Jurado (1991) p. 22.

15 El caso más emblemático fue el de Christian Wolff. En 1723 Federico Guillermo I de Prusia le prohibió enseñar, y se le ordenaba dejar la ciudad de Halle y los dominios reales en cuarenta y ocho horas desde la notificación, bajo pena de galeras. Ello, porque, en opinión de la autoridad civil, sus enseñanzas a favor del determinismo teológico aumentarían la deserción militar. Su idea de que los actos humanos están predeterminados daba a entender que los soldados no podían manejar la deserción (FInKIn y PosT (2009) pp. 146 y ss.

16 Longam (1996) p. 9.

17 Cf. Caceres (2014) p. 5: las ONG son "colectivos que promueven procesos de desarrollo y democratización en y desde la sociedad civil con una perspectiva de derechos", y "asumen una perspectiva de derechos, incluyendo la equidad de género y la interculturalidad".

18 La corrección política es una estrategia de dominación del lenguaje, cercana a ideologías de izquierda, que consiste en establecer criterios y paradigmas de lo que resulta ofensivo a la "dignidad" de las minorías, y que, en consecuencia, propugna la erradicación del ámbito público de cualquier discurso contrario a sus postulados. Como dice Feldstein, "el debate sobre la influencia de las formas representacionales es crucial para entender el énfasis puesto en la distribución del conocimiento desde la segunda mitad del siglo XX. Esta red puede ser manipulada para producir identidades culturales", FELDSTEIN (1997) p. 2.

19 ECE, n. 12. 
que garantiza y completa su dimensión individual, constituida por la libertad de cátedra ${ }^{20}$. ¿Cómo debe entenderse este concepto? El cuerpo de la Constitución Apostólica no define la libertad académica; pero la nota quince sí lo hace, en base a otros textos pontificios, afirmando que "la libertad académica es la garantía dada a cuantos se ocupan de la enseñanza y de la investigación, de poder indagar, en el ámbito del propio campo específico del conocimiento y conforme a los métodos propios de tal área, la verdad por doquiera el análisis y la evidencia los conduzcan, y de poder enseñar y publicar los resultados de tal investigación, teniendo presente los criterios citados, esto es, la salvaguardia de los derechos del individuo y de la comunidad en las exigencias de la verdad y del bien común”. Esta definición es coherente con lo que la doctrina entiende por libertad de cátedra en general (es decir, no relativa exclusivamente a las universidades con ideario). Procedamos a su análisis, de acuerdo a los términos de la Ex Corde Ecclesiae.

a) La libertad académica aparece como una "garantía", es decir, como algo que asegura y protege contra un riesgo o necesidad. Se ofrece seguridad de que, limitada injustamente la libertad para investigar o enseñar, los académicos individualmente considerados, o la comunidad universitaria en general, podrá impetrar los medios necesarios para restablecer el imperio del Derecho al interior del centro universitario. Así, la libertad de cátedra adopta en la Ex Corde Ecclesiae, primariamente, una tonalidad jurídica, tal como ocurre en el Derecho moderno, que la lleva a figurar en muchos lugares con rango de garantía fundamental, recogida en la Constitución ${ }^{21}$. No es una simple pretensión; es un derecho subjetivo que tiene su legítimo correlato en un bien humano básico, consistente en la posibilidad de usar la inteligencia para hacer avanzar el conocimiento y ofrecer los resultados de este trabajo a la comunidad científica.

b) Lo garantizado por este instrumento jurídico es, en primer lugar, la libertad de investigar en cada campo propio y específico del conocimiento; a través de los métodos que son adecuados a dicha área. Tal postulado figura en todas las definiciones de la libertad de cátedra $^{22}$. Esta garantía proviene del objeto mismo de la universidad: aumentar la producción de conocimiento y sus fronteras. Se trata de un requisito imprescindible para que la universidad desempeñe su función propia: alcanzar la máxima verdad posible en cada una de las áreas del saber. Sobre este punto, cabe formular una diferencia con la universidad moderna y laica ${ }^{23}$. Esta, que tiene su origen en los centros universitarios alemanes de la

20 La autonomía se fundamenta en el principio de libertad académica, que se manifiesta en las libertades de cátedra, de investigación y de estudio. Se entiende que la "libertad académica" es más amplia que la libertad de cátedra. Para el Tribunal Constitucional español por ejemplo, la libertad académica es libertad de enseñanza e investigación, es decir, es la libertad de cátedra, o "libertad científica" en la tradición alemana, que incluye docencia e investigación (MEILÁN (1999) p. 380).

21 Es el caso, por ejemplo, de la Constitución de Alemania.

22 Sobre la libertad de cátedra y los límites de la investigación científica, véase MeTzGer (1978) p. 102.

23 Es frecuente en nuestro tiempo que se oponga la universidad confesional o con ideario a la universidad "laica" o "neutral". Así, solo la segunda gozaría del pluralismo metodológico necesario para alcanzar realmente el objetivo académico (no la "verdad", por cuanto esta noción sería también sesgada), mientras que la primera no sería más que un remedo de una institución verdaderamente "científica". Sin embargo, la supuesta neutralidad 
época ilustrada, entiende la verdad exclusivamente como un producto de la razón humana, reduciéndola a la verificación y a la deducción de los principios experimentales ${ }^{24}$. Este modelo de ciencia, para el cual lo único que sería accesible al conocimiento científico, además de la lógica y las matemáticas, serían los hechos, junto con la "legalidad" empírica que con ellos se manifiesta, es ajeno a la idea de unidad trascendental del saber, y a la de unificación existencial de la búsqueda de la verdad ${ }^{25}$. Guardando las distancias (como ocurre con todos los ejemplos), esta diferencia es semejante a la que media entre la intuición del ser y la duda metódica. En el primer caso, el discernimiento del ente por parte de la inteligencia tiene por antecedente realidades indemostrables, que proporcionan el marco de condiciones para que opere el conocimiento (el principio de no contradicción y el de identidad); el hecho de que sean indemostrables no implican su inexistencia ${ }^{26}$. En el segundo caso, la expresión "duda metódica" hace referencia al procedimiento por el cual Descartes intenta despejar los "prejuicios y las opiniones preconcebidas", con objeto de fundar las "bases sólidas" de la nueva ciencia que intenta ${ }^{27}$. Traducida esta cuestión metodológica al ámbito de la verdad, en la primera tesis algo se dice verdadero o falso por relación a su fundamento; y en la segunda, sin dejar de reconocerse todavía la existencia de la verdad, estima que esta se plantea más bien como coherencia entre las premisas y las conclusiones.

Con estos presupuestos, es natural que se abran diferentes genealogías para la noción de libertad académica. Para una universidad que tiene por misión proclamar la verdad de Cristo en la unidad de la fe y de la razón, y que desde esas premisas se consagra sin reservas a la causa de la verdad, porque el saber y la razón son fieles servidores de la $\mathrm{fe}^{28}$, la libertad de cátedra no es una tribuna sin contenido, sino más bien un instrumento precioso para una reflexión continua sobre el saber humano, a la luz de dicha $\mathrm{fe}^{29}$. Esta es la razón de por qué, en una universidad católica, los profesores pueden investigar cualquier ámbito o aspecto de la realidad; incluso el más controvertido, y continuar sus investigaciones hasta donde estas les conduzcan, pero con el límite de los derechos de las personas y de la comunidad; las exigencias de la verdad y del bien común ${ }^{30}$. Estas "exigencias de la verdad" también se encuentran explicitadas por la Constitución Apostólica. Veamos a qué se refiere.

b.1) Los profesores -o al menos la mayoría de ellos-, como cada miembro de la comunidad universitaria, deben tener una inspiración cristiana. Esto quiere decir, como

resulta imposible de alcanzar en el ámbito práctico y real, lo que deriva en que las pretendidas instituciones "neutrales" son en realidad cuerpos académicos que se oponen de hecho a los puntos de partida declarados por las que poseen "ideario". Cf. KinCHeloe (2008) pp. 265 y ss., y Davis (1975) pos. 772 (edición Kindle).

24 Sobre la universidad alemana, PAULSEN (1906) pp. 228 y ss.

25 LARENZ (2001) p. 57.

26 "Quia parvus error in principio magnus est in fine, secundum Philosophum in primo Cali et Mundi, ens autem et essentia sunt quæ primo intellectu concipiuntur...", SANTO TOMÁS DE AqUino, De ente et essentia, Proemio.

27 Descartes, Meditaciones metafisicas, AT VII, 17; Discurso del método, AT VI, 31.

28 ECE, n. 4

29 ECE, n. 13.

30 ECE, n. 12 y n. 29. 
indica el Código Canónico, que la autoridad competente, según los estatutos, debe procurar que, en las universidades católicas, se nombren profesores que destaquen no solo por su idoneidad científica y pedagógica, sino también por la rectitud de su doctrina e integridad de vida (doctrinae integritate et vita probitate)" ${ }^{31}$ ¿Qué quiere decir "rectitud de su doctrina"? La Ex Corde Ecclesiae lo indica con claridad: "en una universidad católica, los ideales, las actitudes y los principios católicos penetran y conforman las actividades universitarias según la naturaleza y la autonomía propia de tales actividades", de tal modo que debe ser, por una parte, una "comunidad de estudiosos", y por otra, una institución académica donde "el catolicismo está presente de manera vital"32. La naturaleza y autonomía de la investigación científica; la tarea más relevante de la vida académica, debe realizarse por lo tanto con una inspiración católica. Pero no es solo eso. La Constitución Apostólica dice expresamente, en sus Normas Generales, que "en los modos concordes con las diversas disciplinas académicas, todos los profesores católicos deben acoger fielmente, y todos los demás docentes deben respetar la doctrina y la moral católicas en su investigación y en su enseñanza" 33 .

b.2) Lo anterior significa, a la luz de los textos, lo siguiente: (i) que los académicos examinen a fondo la realidad; (ii) que las conclusiones sobre esa realidad sean constructivas del diálogo entre ciencia y fe; (iii) que ayude a los hombres en la búsqueda constante de la verdad (entendida como la verdad del que busca la certeza, pero conoce al mismo tiempo la fuente de esa certeza); (iv) que se encuentre abierta a una preocupación ética, y (v) que posea o se encuentre también abierta a una perspectiva teológica ${ }^{34}$.

b.3) Todo lo dicho constituye, pues, una exhortación a los académicos de la universidad católica, ya sea que compartan la fe de la institución; o, no compartiéndola, se hayan comprometido a respetarla, para que no defiendan o mantengan, en su investigación ni en los frutos de ella (conferencias, publicaciones, etc.), tesis u opiniones contrarias a la doctrina católica -Revelación, Magisterio- y al diálogo entre razón y fe; no pudiendo invocarse la libertad de cátedra para hacer lo contrario; por cuanto los límites de esta están establecidos por las exigencias de la verdad, cuyos márgenes quedan determinados por el horizonte de significado que propone la Constitución Apostólica Ex Corde Ecclesiae; y que pueden ser deducidos, además, del Magisterio en su conjunto.

b.4) Hay, junto a este sentido negativo de la libertad de cátedra como límite; un sentido positivo, en el cual se entiende que la universidad católica, a través de sus académicos y de sus autoridades, no solo debe cuidar la verdad y protegerla de toda doctrina que se aparte de su inspiración matriz y vivificante, sino, además, defenderla, mediante el testimonio, cuando las circunstancias lo requieran, ante la sociedad y para la sociedad. Lo

\footnotetext{
31 Código Canónico, canon 810. Lo destacado es nuestro.

32 ECE, n. 14.

33 ECE, II, n. 3.

34 ECE, n. 15.
} 
anterior realza en sentido apostólico de las universidades católicas, en cuanto instituciones de la Iglesia, y constituye la razón por la que se afirma que "si es necesario, la Universidad Católica deberá tener la valentía de expresar verdades incómodas, verdades que no halagan a la opinión pública, pero que son también necesarias para salvaguardar el bien auténtico de la sociedad" 35 , y sin perjuicio de la referencia a la necesaria fidelidad de las universidades católicas al mensaje cristiano (n. 27).

c) Además de la investigación, la libertad de cátedra protege la docencia; es decir, la comunicación a grupos letrados (alumnos) de las conclusiones de la investigación. Todo lo dicho respecto de aquella, es también válido para esta. Se entiende que los docentes universitarios deben esforzarse por mejorar su propia competencia, y "por encuadrar el contenido, los objetivos, los métodos y los resultados de la investigación de cada una de las disciplinas en el contexto de una coherente visión del mundo"36. ¿Qué quiere decir esta expresión, "coherente visión del mundo"? Su significado debe ser comprendido a la luz de la misma Constitución Apostólica, a propósito de la tarea de las universidades católicas, consistente en la unificación de dos órdenes de realidades que a menudo se tienden a oponer como fuerzas antitéticas; a saber, el mundo de la ciencia; que busca la verdad, y el mundo de la fe, que conoce ya de antemano la fuerza de esa verdad ${ }^{37}$. Por lo tanto, el contenido, los objetivos y los métodos de la docencia de los profesores de las universidades católicas, profesen ellos mismos o no la fe y la doctrina de la institución, debe ajustarse a esta coherencia, en el sentido de que no se puede apelar a la libertad de cátedra para enseñar, como verdaderos, contenidos -cualquiera que ellos sean- contrarios a la unidad del saber humano iluminado por la fe. Del mismo modo, los objetivos de enseñanza de tales contenidos no pueden contradecir o negar dicha unidad del conocimiento; ni menos los métodos empleados para conseguirlos. La Ex Corde Ecclesiae indica que "los docentes cristianos están llamados a ser testigos y educadores de una auténtica vida cristiana, que manifieste la lograda integración entre fe y cultura, entre competencia profesional y sabiduría cristiana ${ }^{38}$. Esto quiere decir que, además de la integridad de la doctrina enseñada, que se exige a todos los docentes -católicos y no católicos-, los profesores que se declaran católicos deben dar testimonio de vida; es decir, se les pide también la integridad de vida. Tal cosa, sin embargo, no quiere decir que los docentes que no comparten la fe de la universidad puedan situarse al margen de la ley natural -coherente con los principios de la doctrina católica-. Por esto, se exige que "todos los docentes deberán estar animados por los ideales académicos y por los principios de una vida auténticamente humana”39.

d) El límite que establece el texto a la libertad de cátedra es "la salvaguardia de los derechos del individuo y de la comunidad en las exigencias de la verdad y del bien común”.

\footnotetext{
35 ECE, n. 32.

36 ECE, n. 22

37 ECE, n. 1.

38 ECE, n. 22.

39 ECE, n. 22.
} 
La primera cuestión, de naturaleza jurídica, es una referencia al derecho común; y por lo tanto, no requiere mayor atención como parte del texto de la Constitución Apostólica. De hecho, el n. 29 reitera estos requisitos, pero omite la referencia a los derechos individuales.

Por su parte, la noción de "bien común" hace referencia a la sociedad en la cual se encuentra inserta la universidad; por cuanto el bien común de la comunidad universitaria consiste en la fidelidad a las exigencias de la verdad. Dicho de otro modo: el servicio al bien común procede en primer lugar de esa fidelidad a la verdad de la comunidad toda; cada segmento según sus propias circunstancias: "la universidad católica persigue sus propios objetivos también mediante el esfuerzo por formar una comunidad auténticamente humana, animada por el espíritu de Cristo. La fuente de su unidad deriva de su común consagración a la verdad; de la idéntica visión de la dignidad humana y, en último análisis, de la persona y del mensaje de Cristo, que da a la institución su carácter distintivo" ${ }^{40}$.

El límite por excelencia, es decir, el límite en sentido formal; que se refiere a la naturaleza misma de la institución universitaria, es el que dice relación con la noción de verdad que ya hemos descrito: ni la investigación ni la docencia (ni la difusión, en otro nivel) que se produzca dentro de una universidad católica puede ser contraria a este esfuerzo esencial de la institución, en cuanto parte de la Iglesia Católica ${ }^{41}$, por difundir el mensaje de Cristo; y propiciar la unidad del saber.

Por último, podría alguien argumentar que todas las normas anteriores se refieren exclusivamente a los profesores que se desempeñan en las Facultades de Teología, no aplicándose (o aplicándose de un modo más laxo) a los académicos de otras unidades. Esto, sin embargo, no es así. En primer lugar (1), porque la ECE no formula tal distinción cuando se refiere al tema, en el n. 22. Además (2), porque las facultades de Ciencias Sagradas se abordan de modo específico en otros lugares ${ }^{42}$, y, finalmente (3), porque cuando se habla

\footnotetext{
40 ECE, n. 21.

41 ECE, n. 27.

42 Cf. por ejemplo: Declaración Gravissimus Educationis, sobre la educación cristiana, n. 11: "La Iglesia espera mucho de la laboriosidad de las Facultades de ciencias sagradas. Ya que a ellas les confía el gravísimo cometido de formar a sus propios alumnos, no solo para el ministerio sacerdotal, sino, sobre todo, para enseñar en los centros eclesiásticos de estudios superiores; para la investigación científica o para desarrollar las más arduas funciones del apostolado intelectual. A estas facultades pertenece también el investigar profundamente en los diversos campos de las disciplinas sagradas de forma que se logre una inteligencia cada día más profunda de la Sagrada Revelación, se descubra más ampliamente el patrimonio de la sabiduría cristiana transmitida por nuestros mayores, se promueva el diálogo con los hermanos separados y con los no-cristianos y se responda a los problemas suscitados por el progreso de las ciencias"; Discurso del papa Juan Pablo II a los profesores de teología en la Universidad Pontificia de Salamanca (1 de noviembre de 1982): "la tarea del teólogo lleva pues el carácter de misión eclesial, como participación en la misión evangelizadora de la Iglesia y como servicio preclaro a la comunidad eclesial. Aquí se funda la grave responsabilidad del teólogo, quien debe tener siempre presente que el Pueblo de Dios, y ante todo los sacerdotes que han de educar la fe de ese Pueblo, tienen el derecho a que se les explique sin ambigüedades ni reducciones las verdades fundamentales de la fe cristiana. "Hemos de confesar a Cristo ante la historia y ante el mundo con convicción profunda, sentida y vivida, como la confesó Pedro: Tú eres el Cristo, el Hijo de Dios vivo. Esta es la Buena Noticia, en cierto sentido única: la Iglesia vive por ella y para ella, así como saca de ella todo lo que tiene para ofrecer a los hombres", Discurso en la inauguración de la III Conferencia general del episcopado latinoamericano en Puebla, I, 3, 28, "Debemos servir a los hombres y mujeres de nuestro tiempo. Debemos servirles en su sed de verdades totales; sed de verdades últimas y definitivas, sed de la Palabra de Dios, sed de unidad entre los cristianos", Discurso en la universidad Gregoriana de Roma, 6.
} 
de la misión de la Iglesia, se corre en ocasiones el riesgo de pensar que esto corresponde solo a los sacerdotes y consagrados. Sin embargo, la misión que Cristo encomienda a sus discípulos debe ser ejecutada por todos los que constituyen su Iglesia, quienes, de acuerdo con su propia condición, deben cooperar de modo unánime a la tarea común ${ }^{43}$. De hecho, el Concilio Vaticano II expresa que "la vocación cristiana es, por su propia naturaleza, vocación al apostolado... Hay en la Iglesia diversidad de funciones, pero una sola misión. A sus Apóstoles y a sus sucesores les confirió Cristo el ministerio de enseñar, de santificar y de gobernar en su propio nombre y autoridad. Pero los laicos, al participar de la función sacerdotal, profética y real de Cristo, cumplen en el mundo su función específica dentro

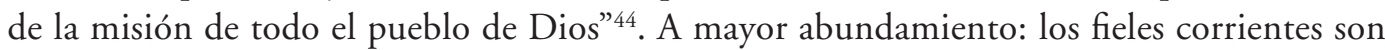
llamados a contribuir desde dentro a la santificación del mundo, mediante el ejercicio de sus propias tareas ${ }^{45}$.

Así pues, la llamada al apostolado es una llamada universal, no solo a los consagrados o a los profesores de las facultades de Teología. El apostolado de la verdad, que es el propio de una universidad católica, constituye la peculiaridad de la misión apostólica para todos los académicos que en ella se desempeñan, ya sea promoviendo activamente la conversión de los corazones a través de la verdad natural iluminada por la fe, o a través del respeto de esta, que contiene el abstenerse de combatirla, implícita o explícitamente. Incluso, se afirma que los laicos (entre los que se encuentran los profesores de una universidad católica, llamados a realizar el apostolado a través de su tarea específica) son llamados a evitar "la tentación de legitimar la indebida separación entre la fe y la vida, entre la recepción del Evangelio y la acción concreta en las más diversas realidades temporales y terrenas" ${ }^{\text {"6 }}$.

\section{LA LIBERTAD DE CÁTEDRA DE LA EX CORDE ECCLESIAE EN SU DIMENSIÓN EPOCAL}

La noción católica de libertad de cátedra fue dominante hasta la modernidad. Esta última se caracteriza por una disociación de ciertos principios que en el tiempo clásico se encontraban unidos; como el ámbito de la naturaleza y del espíritu ${ }^{47}$. Consiste también en un redescubrimiento de la razón, al estilo de la hipótesis grociana del Etiamsi Daremus; una

\footnotetext{
43 Lumen Gentium, n. 17.

44 Apostolicam actuositatem, n. 2.

45 Lumen Gentium, n. 31. Lo destacado es nuestro.

46 Christifidelis laici, n. 2.

47 En las Meditationes metafísicas Descartes ofrece una explicación sistemática del dualismo metafísico entre la mente y el cuerpo, que ha tenido gran influencia en el pensamiento posterior. Para Descartes, hay dos sustancias creadas diferentes, el cuerpo y el alma (a la que también denomina 'mente'). La esencia del cuerpo es la extensión; mientras la del alma o mente es el pensamiento. El cuerpo es espacial, el alma no tiene extensión. El cuerpo es un mecanismo que puede ejecutar muchas acciones sobre sí mismo sin la intervención del alma; el alma es pura sustancia pensante que puede, pero no siempre, regular el cuerpo. Cómo el cuerpo espacial puede afectar o ser afectado por la mente no extensa, no puede ser comprendido, para Descartes, ni en términos espaciales ni no espaciales. Está más allá de nuestra capacidad de comprender cómo el cuerpo y la mente están unidos, o, en el mejor de los casos. De hecho, en una carta fechada en 1640, Descartes sostiene que solo cabe concluir que el alma no se encuentra unida inmediatamente a ninguna parte sólida del cuerpo. AT VII, 86, y AT III, 264 (carta a Mersonne).
} 
especie de desteologización de la condición humana que se pone a disposición de la razón liberadora, la cual promete alejar al hombre de los males propios de su condición mortal.

Se puede decir también que este período, o esta sensibilidad moderna, coincide con el surgimiento pleno de los Estados nacionales. Se produce un auge del humanismo que enfatiza lo singular y las lenguas vernáculas, apoyado por el invento de la imprenta. Así, la relativa autonomía de las universidades es sistemáticamente obstaculizada por naciones emergentes como Francia, España e Inglaterra, o las ciudades-estado italianas ${ }^{48}$.

En los siglos XVIII y XIX, la universidad es concebida como la institucionalización de la idea de Bildung; es decir, del libre cultivo y desarrollo de las facultades humanas, de un modo comprensivo y extensivo; tanto a través de las ciencias como más allá de ellas ${ }^{49}$. El objetivo de la educación académica era formar sujetos esencialmente libres; abiertos de un modo absoluto a todo el campo de la experiencia humana; a diferencia de la idea del hombre en sentido trascendente que era propia de la universidad clásica, que era visto como “constreñido" por las reglas escolásticas ${ }^{50}$.

Fruto de la inspiración ilustrada, la libertad adquiere un valor central para la universidad moderna ${ }^{51}$. Los alumnos debían ser considerados más bien como colaboradores en el desarrollo científico, antes que como educandos; en ningún sentido como almas sobre las que cabía hacer apostolado. Esta fue una de las razones para la creación de los seminarios en la moderna universidad alemana: para hacer más autónomos a los individuos; estos -según el modelo que describimos- necesitan grandes cantidades de libertad, en la medida en que su desarrollo depende de su capacidad de expresarse libre y responsablemente. Por ello en la universidad del siglo XIX era tan importante la Lernfreiheit, o libertad de aprendizaje o estudio, que incluía la libertad de escoger los cursos, incluso en más de una universidad; y de dar sus exámenes finales cuándo y dónde quisieran ${ }^{52}$.

Puede afirmarse que la modernidad, como constante epocal, se extiende hasta mediados del siglo XX; concretamente, hasta después de la Segunda Guerra Mundial, que sepulta definitivamente, desde el punto de vista cultural, los grandes relatos a que se refiere Lyotard, quien define a la posmodernidad como un estado de la cultura después de las transformaciones que han afectado a las reglas de juego de la ciencia, la literatura y de las artes, y a los metarrelatos como proyectos que legitimaban y fundamentaban las instituciones y las prácticas públicas, sociales y políticas ${ }^{53}$. Una vez que se extinguen estas narraciones, el modelo metodológico queda a disposición de una hermenéutica sin base esencial, que deriva en las grandes teorías de la liberación del significante, como el caso de Derrida, cuya importancia para definir la época contemporánea es indiscutible a través de las ideas de huella originaria y deconstrucción ${ }^{54}$.

48 SCOTT (2006) p. 10.

49 FICHTE (1817): sección primera, n. 5: "la libre actividad de concebir se llama intelecto".

50 "Contemplad vuestro estudiante libre, heredero de la cultura libre", afirma Nietzsche. Nietzsche (1872) quinta conferencia.

51 Ruegg (1996) p. 122.

52 Para una diferencia entre esta noción, y la Lehrfreiheit, véase ZACHER (1970) pp. 108 y ss.

53 Lyotard (2006) p. 26.

54 CoHen (2005) p. 123. 
La universidad, como institución cultural, no ha sido ajena a este proceso de deconstrucción en la tardomodernidad. Tal como ha ocurrido desde los sofistas en adelante en la historia occidental, cuando se suprimen los sentidos o significados universales, estos son normalmente reemplazados por estrategias de poder ${ }^{55}$. Así, muchas veces la universidad es concebida, sin que ello sea manifestado de forma expresa ni programática, como un dispositivo, es decir, como una red entre diversos elementos que tiene una relación estratégica concreta, y se inscribe siempre en una relación de $\operatorname{poder}^{56}$.

Dentro de este fenómeno, cuyo análisis no ha hecho sino comenzar, la libertad de cátedra ha sufrido una nueva mutación, que debe ser tenida en cuenta a la hora de evaluar el concepto de libertad académica que hemos expuesto, fundados en la Constitución Apostólica Ex Corde Ecclesiae. Si para la modernidad la experiencia de la verdad era semejante a una vasija sin contenido, para la universidad postmoderna, globalizada y multicultural, se parece más bien a la defensa institucional de los derechos y garantías de los diferentes grupos que componen la sociedad en sentido global; especialmente de los grupos minoritarios. Tesis como la ponderación de los bienes en la sociedad (el balancing test) -en lugar de su jerarquización racional-, o el garantismo, según el cual el Estado solo existe para garantizar los derechos de los ciudadanos, se trasladan a otras organizaciones intermedias, como los centros universitarios. Así, la noción de libertad de cátedra va mutando paulatinamente hasta convertirse en un derecho absoluto, incluso más allá de límites tradicionales; que además no requiere ser justificado porque, como todo "nuevo derecho", queda sustentado por la simple libertad de conciencia.

Se genera así un conflicto entre las universidades con ideario y la mencionada concepción de la libertad de cátedra como una exigencia materialmente absoluta. Se trata de una cuestión que va más allá de lo jurídico; por cuanto muchos de los académicos que sostienen posiciones contrarias a las exigencias de la verdad, en el sentido que le otorga la Ex Corde Ecclesiae, han firmado previamente un documento en el que se comprometen a respetar los principios de las universidades católicas. Los textos normativos, por lo tanto, a menudo se convierten en letra muerta.

Otra manera de expresar esta situación es sostener que chocan dos concepciones diferentes de lo jurídico: una que defiende bienes esenciales y generales; y otra que defiende exigencias jurídicas subjetivas. En este sentido, la ineficacia a que se ven sometidas las explícitas proposiciones de conducta expresadas en la Constitución Apostólica, relativas al respeto a la doctrina católica en la investigación, la docencia y la difusión universitarias, se debe a la primacía fáctica del segundo modelo sobre el primero; lo que implica un cambio de paradigma cultural que debe ser asumido por las autoridades de la Iglesia; no para cambiar la verdad de los principios, sino para encontrar las propuestas metodológicas necesarias para que la universalidad de la doctrina pueda ser afirmada, sostenida y defendida en medio de una sensibilidad cultural crecientemente hostil. Esto es un trabajo que se plantea primariamente en términos teóricos; plataforma desde la cual debiera descender hasta los ámbitos más específicamente prácticos del saber y del actuar universitario.

55 Kogan (2007) pp. 40 y ss.

56 Agamben (2011) p. 250. 


\section{CONCLUSIONES}

La concepción de la libertad de cátedra que contiene la Constitución apostólica Ex Corde Ecclesiae gira en torno a las raíces más profundas de la existencia de la universidad católica: encontrar y gozar la verdad de acuerdo con las exigencias de un saber que se abre a la unidad de la fe y de la razón; constituyendo un bien intrínsecamente difusivo que colabora no solo con la formación intelectual de maestros y discípulos, sino que también, y muy principalmente, con el conocimiento moral que forma hombres buenos y virtuosos, capaces de alcanzar las promesas sobrenaturales que Cristo, Señor de la historia, despliega para aquellos que pueden "ver y oír" 57 . Es labor de los centros universitarios católicos ayudar a ver y oír al pueblo de Dios a través del ejercicio de la inteligencia y del pensamiento abstracto; aplicado especialmente a la comprensión de los grandes problemas de la sociedad y la cultura ${ }^{58}$ y a las preocupaciones éticas permanentes del hombre ${ }^{59}$.

Dentro de este paradigma hermenéutico, que otorga un horizonte de significado específico, denso y riquísimo a la comprensión de las llamadas exigencias de la verdad, de la persona y del bien común, la libertad de cátedra que se configura desde la Ex Corde Ecclesiae está plena de contenido; solo guarda la indeterminación propia de las conclusiones respecto de los principios, y requiere para ello del recto discernimiento por parte de las respectivas autoridades universitarias para hacerla efectiva en la vida de las comunidades académicas; unida a la decisión de ejercerla, y respetando la libertad de conciencia de cada cual $^{60}$. Esta decisión de ejercer efectivamente la dimensión operativa de la libertad de cátedra en el sentido expuesto es una obligación grave, a la luz de lo expresado por la Constitución Apostólica, pero también al tenor de otros textos, como por ejemplo, el canon 809 Código de Derecho Canónico.

Lo distintivo de la noción de libertad de cátedra propuesta por la Ex Corde Ecclesiae radica en que la Iglesia, al aceptar la legítima autonomía de la cultura humana y especialmente de las ciencias, reconoce también la libertad de cada estudioso en la disciplina de su competencia, de acuerdo con los principios y métodos de la ciencia a la que ella se refiere ${ }^{61}$; pero inscritas en el paradigma hermenéutico de las exigencias de la verdad y del bien común ${ }^{62}$. Por ello, la comunidad universitaria estará animada por un espíritu de libertad y de caridad, caracterizada por el respeto recíproco, el diálogo sincero y la tutela de los derechos de cada uno ${ }^{63}$.

Es preciso ser cuidadoso, sin embargo, en no confundir el deber de proclamar el mensaje de Cristo con el proselitismo o el adoctrinamiento, en perspectiva político-ideológico-partidista. Las materias seculares deben ser investigadas y enseñadas por su valor intrínseco, y medidas por los estándares y normas propios y aplicables a cada disciplina

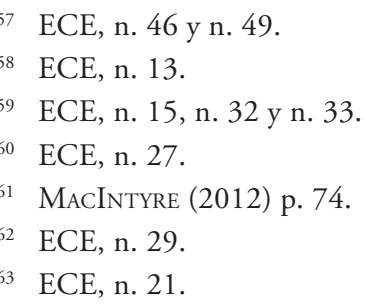


considerada en particular ${ }^{64}$. Solo a partir de esta objetividad, se puede producir la verdadera unión de ciencia natural y fe, que constituye el objetivo de la universidad católica, y el correcto uso de su libertad académica; en sentido amplio.

En virtud del cambio de paradigma en la concepción de la ciencia y de la verdad al que nos referíamos antes, esta idea fundacional y llena de sentido de la libertad de cátedra va perdiendo terreno cultural e históricamente hablando a lo largo del tiempo, hasta llegar a constituir hoy en día, más que la regla general, la excepción a la hora de explicar el modo en que deben comportarse los académicos en su investigación y docencia. Sin embargo, este "perder terreno" solo es cuantitativo; no indica una disminución de la fuerza fundante y racional del significado católico de la libertad de cátedra. Dicho de otro modo, lo que ha ocurrido es, más que una superación de los principios fundantes de dicha libertad académica, un cambio tan radical en la comprensión del tema que la cultura contemporánea del mundo occidental tiene dificultades para entender el hondo significado de aquellos principios y postulados que configuran su propia tradición.

El problema radica en que estos nuevos paradigmas, que declaran a la hermenéutica libre como valor supremo, se comportan de un modo extraño y agudamente restrictivo a la hora de permitir que las instituciones de educación superior católicas desempeñen su trabajo dentro del horizonte de significado de la exigencia de verdad. Se establecen parámetros lingüísticos de "decencia" y "probidad" que entrañan un contenido muchas veces contrario a la doctrina católica, y se exige de los miembros de las comunidades universitarias cristianas su "respeto"; tanto desde el interior como desde el exterior de ellas; basados en la globalización (por ejemplo, a través del concepto de democracia) y el multiculturalismo, que entroniza a la "diversidad" como un bien primario. Es el caso de la llamada "corrección política”, a la que antes se hacía referencia, cuyo mensaje y contenido en bastantes ocasiones representa un conflicto con las doctrinas y principios que encarna la universidad católica, pero cuyo estándar es exigido a esta como si fuera su propio código de bienes y valores.

En este contexto cultural, la noción de libertad académica que expone y desarrolla la Constitución Apostólica Ex Corde Ecclesiae no puede convertirse en operativa sino a través de una reformulación de su dimensión metodológica; es decir, de su reconfiguración como valor hermenéutico, a través de la recuperación de la idea de verdad abierta a la trascendencia, y capaz de encarnar el sentido profundo de universidad como universalidad del conocimiento; es decir, como un saber que abarca la razón y la fe, pero alcanzado dialécticamente a través de su confrontación con las teorías dominantes de nuestro tiempo; en otros términos, mediante la configuración de las garantías para un apostolado de la verdad que se haga cargo de todas las objeciones contemporáneas, a partir de los principios contenidos tanto en ECE como en todos los textos en que esta se apoya.

64 Simboli (2012) p. 326. 


\section{BIBLIOGRAFÍA CITADA}

AAVV (1993): Catholic Universities in Church and Society. A Dialogue on Ex Corde Ecclesiae, (ed. Langam, John P., Washington D.C., Georgetown University Press).

AAVV (1999): Código de Derecho Canónico (Madrid, Biblioteca de Autores Cristianos).

Agamben, Giorgio (2011): “¿Qué es un dispositivo?”, Sociológica, No 73: pp. 249-264.

Aquino, Santo Tomás de (2002): De ente et Essentia (trad. Eudaldo Forment, Pamplona, EUNSA).

Bennington, Jeoffrey (2005): "Derrida y la política”, en Cohen, Tom (edit.), Jacques Derrida y las humanidades (Ciudad de Méjico, Siglo XXI) pp. 249-272.

Davis, Bertram H. (1975): "Academic Freedom, Academic Neutrality, and the Social System", en Pincoffs, E. (ed.), The Concept of Academic Freedom (Austin, University of Texas Press) pp. 27-36.

Descartes, René (1902): Meditationes de prima philosophia, vol. VII (eds. Adam, Charles y Tannery, Paul, París, Cerf).

Descartes, René (1902): Discours de la Méthode, vol. VI (eds. Charles Adam y Paul Tannery, París, Cerf).

Derrida, Jacques (1985): "Cátedra vacante. Censura, maestría y magistralidad”, en Texte, No. 4. Existe versión española en (1995): El lenguaje y las instituciones filosóficas (trad. Grupo Decontra, Barcelona, Paidós).

Feldstein, Richard (1997): Political Correctness. A Response from the Cultural Left (Minneapolis, University of Minnesota Press).

Fichte, Johann (1958): "Plan razonado para erigir en Berlín un establecimiento de enseñanza superior que esté en conexión adecuada con una Academia de Ciencias", en AAVV, La idea de la universidad en Alemania (Buenos Aires, Editorial Sudamericana) pp. 15-115.

Finkin, Matthew y Post, Robert (2009): For the Common Good. Principles of American Academic Freedom (New Haven, Yale University Press).

Heft, L. James y O'donovan, Leo (1996): "A University that Evangelizes? Ex Corde Ecclesiae six years afterwards", Horizons, Vol. 23, No. 1: pp. 103-112.

Kincheloe, Joe (2008): “The Importance of Ideology in Contemporary Education”, en Bartolomé, Lilia I. (ed.), Ideologies in Education. Unmasking the Trap of Teacher Neutrality (Nueva York, Peter Lang Publishing) pp. 265-270.

Kogan, Maurice (2007): “Modes of Knowledge and Patterns of Power”, en Sörlin, Sverker y Vessauri, Hebe (eds.), Knowledge Society versus Knowledge Economy (Nueva York, Palgrave McMillan) pp. 35-54.

Larenz, Karl (2001): Metodología de la ciencia del Derecho (Madrid, Ariel).

Leguina Villa, Joaquín y Ortega Álvarez, Luis (1982): "Algunas reflexiones sobre la autonomía universitaria”, REDA, $\mathrm{N}^{\circ}$ 35: pp. 547-565.

Lopez-Jurado, Francisco de Borja (1991): La autonomía de las universidades como derecho fundamental: la construcción del Tribunal Constitucional (Madrid, Civitas).

LYOTARD, Jean-François (2006): La condición postmoderna (Madrid, Cátedra). 
MacIntyre, Alasdair (2012): Dios, filosofía, universidades. Historia selectiva de la tradición filosófica católica (Granada, Nuevoinicio).

MADrid, Raúl (2013): "El derecho a la libertad de cátedra y el concepto de universidad", Revista Chilena de Derecho, vol. 40, N 1: pp. 353-369.

Meilán, José Luis (1999): "La autonomía universitaria desde una perspectiva constitucional", Anuario da Facultade de Dereito da Universidade da Coruña, No 3: pp. 369-396.

Metzger, Walter P. (1978): "Academic Freedom and Scientific Freedom”, Daedalus, vol. 107, $\mathrm{N}^{\circ}$ 2, Limits of Scientific Inquiry: pp. 93-114.

Morandé, Pedro (2011): "La vocación de servicio de la universidad a las personas y a la sociedad”, en Constitución Apostólica Ex Corde Ecclesiae, con reflexiones de destacados académicos (Santiago, Pontificia Universidad Católica de Chile) 99 pp.

Nietzsche, Friedrich (1958): "El porvenir de nuestros establecimientos de enseñanza”, primera edición en 1896. Recogido en AAVV, La idea de la universidad en Alemania (Buenos Aires, Editorial Sudamericana) pp. 223-258.

O'Brien, George Dennis (2002): The Idea of a Catholic University (Chicago, The University of Chicago Press).

Paulsen, Friedrich (1906): The German Universities and University Studies (trad. Thilly, F. y Elwang, W., Nueva York, Charles Scribner's Sons).

RuegG, Walter (1992): A History of the University in Europe, vol. I (Cambridge, Cambridge University Press).

RuegG, Walter (1996): A History of the University in Europe, vol. II (Cambridge, Cambridge University Press).

SiLva, José Antonio (2009): "La identidad de la universidad católica”, Cuadernos Doctorales, $\mathrm{N}^{\circ}$ 23: pp. 271-331.

ScotT, John C. (2006): “The Mission of the University: Medieval to Postmodern Transformations", The Journal of Higher Education, vol. 77, $\mathrm{N}^{\circ} 1$ : pp. 1-39.

Simboli, Brian (2012): "Ex Corde Ecclesiae, Social Science and the Public Square", The Catholic Social Science Review, Vol. 17: pp. 323-336.

ZaCHER, Hans (1970): "Lernfreiheit contra Lehrfreiheit?", Mitteilungen des Hochschulverbandes, Band XVIII: pp. 106-113.

\section{DOCUMENTOS PONTIFICIOS}

APOSTOLICAM ACTUOSITATEM, Decreto sobre el apostolado de los laicos, promulgado por SS. Pablo VI el 18 de noviembre de 1965.

CHRISTIFIDELIS LAICI, Exhortación apostólica post-sinodal sobre la vocación y misión de los laicos en la Iglesia y en el mundo, promulgada por SS. Juan Pablo II, promulgada el 30 de diciembre de 1988.

CÓDIGO DE DERECHO CANÓNICO, Promulgado por la Autoridad de SS. Juan Pablo II, el 25 de enero de 1983.

Discurso del papa Juan Pablo II a los profesores de teología en la Universidad Pontificia de Salamanca (1 de noviembre de 1982). 
Discurso de SS. Juan Pablo II en la inauguración de la III Conferencia general del episcopado latinoamericano en Puebla, I, 3, 28 de enero de 1979.

Discurso de SS. Juan Pablo II en la universidad Gregoriana de Roma, 15 de diciembre de 1979.

EX CORDE ECCLESIAE, Constitución Apostólica promulgada por SS. Juan Pablo II el 15 de agosto de 1990.

GAUDIUM ET SPES, Constitución Pastoral sobre la Iglesia en el mundo actual, promulgada por SS. Pablo VI el 7 de diciembre de 1965.

GRAVISSIMUS EDUCATIONIS, Declaración sobre la educación cristiana, promulgada por SS. Pablo VI el 18 de octubre de 1965.

LUMEN GENTIUM, Constitución dogmática sobre la Iglesia, promulgada en la sesión pública del 21 de noviembre de 1964.

VERITATIS SPLENDOR, Carta Encíclica de SS. Juan Pablo II a todos los Obispos de la Iglesia Católica sobre algunas cuestiones fundamentales de la enseñanza moral de la Iglesia, 6 de agosto de 1993. 